NASA Technical Memorandum 101403

\title{
SP-100 Nuclear Space Power Systems With Application to Space Commercialization
}

John M. Smith

Lewis Research Center

Cleveland, Ohio

Prepared for

Space Commercialization: Roles of Developing Countries sponsored by the American Institute of Aeronautics and Astronautics Nashville, Tennessee, March 5-10, 1989 



\title{
SP-100 NUCLEAR SPACE POWER SYSTEMS WITH APPLICATION
}

TO SPACE COMMERCIALIZATION

\author{
John M. Smith \\ National Aeronautics and Space Administration \\ Lewis Research Center \\ Cleveland, Ohio 44135
}

\begin{abstract}
SUMMARY
The purpose of this paper is to familiarize the Space Commercialization Community with the status and characteristics of the SP-100 space nuclear power system. The program is a joint undertaking by the Department of Defense, the Department of Energy and the National Aeronautics and Space Administration. The goal of the program is to develop, validate and demonstrate the technology for space nuclear power systems in the range of 10 to $1000 \mathrm{kWe}$ for use in the future military and civilian space missions. Also discussed are mission applications which are enhanced and/or enabled by SP-100 technology and how this technology compares to that of more familiar solar power systems. The mission applications include earth orbiting platforms and lunar/Mars surface power.
\end{abstract}

\section{INTRODUCTION}

As human visions of space applications expand and as we probe further and further out into the universe so will our needs for power expand, and missions will evolve in which the enabling source will be nuclear. With this in mind and with the realized long lead time for the development of nuclear power devices a tri-agency program involving the Department of Defense (DOD), the Department of Energy (DOE) and the National Aeronautics and Space Administration (NASA) was initiated in 1983. This program has been entitled the SP-100 program being symbolic of the development of a space power system in the nominal $100 \mathrm{kWe}$ category with the present concept scalable from 10 to $1000 \mathrm{kWe}$. In this paper we will briefly address the current status of the SP-100 program and the potential applications for its use on civil space missions.

The utilization of nuclear power for space applications is not new. The Soviets have launched in excess of 30 reactors and several radioisotope generators. The United States has launched a reactor and 22 spacecraft powered by Plutonium 238 radioisotope sources. The U.S. systems have all been at or below $500 \mathrm{~W}$ electric and have used thermoelectrics as the power conversion device. These devices are far too low in power to meet the requirements of SP-100 missions and their technology is such that they are far too heavy and costly on a per kilowatt electric for use at SP-100 power levels.

The SP-100 program has completed the concept development phase in which a lithium cooled, uranium nitride fueled nuclear reactor operating at a peak temperature of $1350^{\circ} \mathrm{K}$ and utilizing conductively coupled thermoelectrics as the power conversion device has been selected for development. The program is presently in a 6 year Ground Engineering System (GES) test phase. In this phase a space traceable version of the nuclear reactor and the power conversion subsystem will be separately tested. This will be followed by a flight demonstration phase which is in the process of being defined. 
A broad spectrum of missions which would be enhanced or enabled by the development of the SP-100 nuclear space power program have been defined. These include earth orbital platforms; earth science and applications experiments; earth orbit, lunar and Mars transport; planetary exploration and extraterrestrial resource exploitation. The most widely investigated of these missions have been the earth orbiting platform and the lunar/Mars base. These applications of the SP-100 Nuclear power system will be reviewed in the paper.

\section{SP-100 NUCLEAR SPACE POWER PROGRAM}

The tri-agency SP-100 program is supported by the Department of Energy, the Department of Defense and the National Aeronautics and Space Administration (DOE, DOD and NASA). The program initiated in 1983 has as its objective the development of a 10 year life ( 7 years at power) space nuclear reactor power system operating in the range of 10 to 1000 kWe for use in future military and civil space missions. The program is being implimented in three phases: Concept Selection, Technology Development and Validation, and Flight Demonstration.

The three year concept selection phase was completed in 1985 . Four power conversion systems were investigated: In-core thermionics, thermoelectrics, Stirling and Brayton. The latter three concepts use a fast spectrum, lithium cooled, uranium nitride fueled nuclear reactor while the in-core thermionic reactor used a 102 fueled NAK cooled reactor.

The investigations were performed and the technology feasibility issues were studied by a team of DOE and NASA Laboratories working with major aerospace companies and associated nuclear reactor companies. All of the concepts were found to be safe and technically feasible. However, after extensive study and a careful weighing of pros and cons, the thermoelectric system was selected for development in Phase II. The Stirling system was recommended for growth to higher power levels and is being developed by NASA under the SP-100 Advance Technology Program.

Under the current Phase II program initiated in 1986 a prototypical SP-100 system is being designed, major components built and will be tested on the ground in a simulated space environment. The project management responsibility resides at the Jet Propulsion Laboratory and the General Electric Co is the System Contractor. A picture of the SP-100 reference flight system is shown in figure 1. The nuclear reactor will be tested in an existing facility at the Hanford Engineering Development Laboratory near Richland, Washington. The power generating subsystem will not be used in this test. A heat rejection system will cool the reactor under all normal and off normal conditions. The ground test is designed to simulate the flight operating conditions so as to establish confidence in the SP-100 reactor design and to resolve technical issues necessary for the development of a flight mission design. The other major components of the system including the thermoelectric power conversion and heat rejections subsystems will be tested elsewhere using a nonnuclear heat source.

Upon successful completion of Phase II testing, SP-100 technology can be available in the 1990's for initial spaceflight demonstration and subsequent use to support civilian and military space missions. The initial spaceflight demonstration of Phase III is still in the planing stage. 


\section{SP-100 REFERENCE FLIGHT SYSTEM DESIGN}

The SP-100 reference flight system (RFS) design is shown in figure 1. Details of this system and its subcomponent designs can be found in references 1 and 2. The RFS is designed to fit into and be deployed along with its payload from the NASA Space Shuttle bay. At its nominal power level of $100 \mathrm{kWe}$ the RFS Space Reactor Power System (SRPS) is stowed ( $f i g .2$ ) by folding the heat rejection radiator panels forward through an approximately $165^{\circ}$ arc toward the reactor via flexible heat pipe joints at the power converter interface section and collapsing the separation boom. Dimensions of the $100 \mathrm{kWe}$ RFS design in its stowed and deployed configurations are shown in figure 3 . Key system performance characteristics and mass breakdown goals are listed in tables I and II. The overall weight goal of the RFS is approximately $4500 \mathrm{Kg}$ such that the power system and a reasonable payload can be launched using either the Space Shuttle or the US Airforce Titan IV launch vehicle.

The RFS design is a living document that will undergo continual update and change as the GES phase of the SP-100 program progresses. Based on the snapshot in time defined by references 1 and 2, a brief description of the major components and major user interfaces is presented in this section.

\section{Nuclear Reactor}

The SP-100 nuclear reactor is a lithium cooled, uranium nitride fueled, fast spectrum reactor. Its nominal design is for $2.5 \mathrm{MW}$ of thermal (MWT) power to assure that $100 \mathrm{kWe}$ can be produced from the thermoelectric converters. The technology is scalable from 10 to $1000 \mathrm{kWe}$. The fuel enrichment, burnup, fission gas storage, and reactor core sizing is such as to produce a 7 year, continuous operating lifetime. PWC-11 (niobium, 1 percent zirconium, 0.1 percent carbon) is used for the reactor vessel and internal structure, the fuel pin cladding and the primary heat transport system components. Twelve beryllium oxide reflector elements externally surrounding the reactor provide control for normal startup, shutdown and power operation. Four boron carbide in-core safety rods are provided to maintain the reactor in shutdown condition for all credible accident scenarios. This includes all combinations of water and soil within and surrounding the reactor with safety rods in place but reflectors in their most reactive position. For this case the core is assumed to be compacted to allow for the adverse effects of an explosion. The reactor also has an independent secondary cooling loop to remove radioactive decay heat and maintain the core temperature at a low enough level $(2000 \mathrm{~K})$ to insure structural integrity and fission product retention in the event of a loss of coolant accident.

\section{Nuclear Reactor Shield}

The shield is a multilayered design employing LiH for neutron attenuation, tungsten for gamma ray attenuation and beryllium for thermal control and structure. The shield is contained in a titanium shell. It is a shadow shield designed to protect the RFS components from the nuclear radiation within a cone of $17^{\circ}$ half angle. This angle was chosen to minimize system mass of the RFS design. The shield is further structured (see figure 4) so as to limit the radiation at the user plane (defined to be $4.5 \mathrm{~m}$ diam., $22.5 \mathrm{~m}$ from reactor) to $1 \times 10^{13}$ neutrons $/ \mathrm{cm}^{2}$ ( 1 Mev equivalent) and $5 \times 10^{5} \mathrm{rad}$ ( $\mathrm{Si}$ equivalent). The 
$4.5 \mathrm{~m} \mathrm{dia}$. user plane is based on the assumption that the user payload is restricted to the Space Shuttle bay diameter and does not deploy any objects outside this diameter.

Heat Transport, Power Conversion and Heat Rejection Loops

Twelve primary heat transport loops carry the nuclear reactor 1 ithium coolant to the hot side of the thermoelectric converters. The lithium coolant is pumped back through the reactor by a dual mode, thermoelectric powered electromagnetic pump. The pump is termed dual since it also serves to pump the lithium coolant for the heat rejection loop through a second passage. The pump uses the temperature differential between the hot primary loop and the cold heat rejection loop to drive its own thermoelectric power unit which has the advantage of being self-starting. Both the pump and main power conversion thermoelectric elements are conductively coupled and made of silicon-germanium doped with gallium-phosphide. The conversion efficiency is expected to be 4 percent or better. Twelve heat rejection loops using lithium cool the cold side of the thermoelectrics and transport the heat to the radiator. The radiator is composed of multiple (454/10op) heat pipes using potassium as the working fluid. The radiator is designed for a 7 year operating life taking into account micrometeorolds and debris. The RFS is capable of operating at full power with only 11 of the 12 loops functioning.

\section{Safety}

The major design issue for the RFS is safety. Safety is the most important issue and is critical if the program is to reach flight status. Flight approval comes only after an extensive review by the independent Interagency Nuclear Safety Review Panel which was established in the 1960's and reviews all U.S. nuclear missions and reports to the Office of Science and Technology Policy, within the Office of the President of the United States. The final launch decision is made by the Director of the Office of Science and Technology Policy or by the President.

The major safety features incorporated in the RFS design are:

(1) The SP-100 reactor is not operated until it is in a nuclear safe orbit, i.e., an orbit in which its life before reentry is sufficient for the radioactivity to decay to safe levels. Therefore there are no radioactive fission products before or during launch.

(2) The use of redundant reflector control elements and redundant safety control rods allow safe control of the reactor under all credible accident scenarios.

(3) The reactor has a secondary coolant loop to assure safe reactor shutdown and maintenance in the event of a loss of coolant accident.

\section{EARTH ORBITING PLATFORM APPLICATIONS}

As the needs for power grow for earth orbit applications nuclear electric power systems become advantageous. As these needs reach hundreds of kilowatts 
electric (kWe) and beyond the use of large solar arrays become increasingly difficult. The nuclear power system has the advantage of simplifying platform dynamics, eliminating the need for continual Sun orientation requirements and, due to its compactness, reduces atmospheric drag in low earth orbit (LEO) with its attendent requirement for propulsive fuel makeup. The compactness of the nuclear system also will facilitate access to the platform by other vehicles, the assembly of large space structures such as antennae and increases the viewing area for on-board experiments and operations. On the disadvantageous side is the heavy nuclear reactor shielding that is required to protect platform instrumentation and/or human beings from the nuclear radiation.

The application of an SP-100 class nuclear power system to an earth orbiting platform has been extensively studied (refs. 3 and 4 ). Both of these studies used the NASA Space Station at a $500 \mathrm{~km}, 28.5$ inclination grbit as a reference platform (present Space Station orbit is $370 \mathrm{~km}, 28.5$ inclination). While the present Space Station orbit does not meet the present SP-100 criterion for nuclear safety, the problems and solutions generated by these studies apply to other earth orbits as well. The utilization of nuclear power in earth orbit will probably only be applicable to advanced platforms beyond the present space station mission. The major issue addressed in both of these studies was that of nuclear radiation protection which is solved by either locating the reactor near human habitants and paying the price in heavy shielding or remotely locating the reactor and transmitting the power which reduces the radiation flux by the square of the distance and hence significantly reduces shielding requirements.

In reference 3 three different methods for coupling the nuclear power system to the platform were investigated. These methods were: attaching the reactor directly to the platform, attaching the reactor via a flexible tether. or locating the reactor on a free-flying power platform. In addition, three options for power transmission were investigated. These options were power transmission by: electrical conduction, fuel transport, or electromagnetic beaming. Fourteen different configurations based on these coupling and transmission methods were investigated and three were considered for detail investigation: a nuclear reactor mounted on a main platform and power transmitted by conduction, a nuclear reactor attached to a mini platform by a long tether and power transported by fuel, and a free-flying nuclear reactor with power transport by fuel using an orbital transfer vehicle. Two power levels and conversion systems were considered. These were a SP-100 based reference case using 5 percent efficient thermoelectric convertors producing $150 \mathrm{kWe}$ and an advanced technology based SP-100 using a Stirling engine producing $300 \mathrm{kWe}$ at 25 percent efficiency.

\section{Platform Mounted Reactor}

A reactor can be mounted directly on the platform and shielded all the way around or it can be deployed on a boom similar to that of the SP-100 Reference Design to benefit from the $1 / r^{2}$ radiation flux reduction and utilize a shadow shield to further reduce the shielding weight. The former solution yields the highest shield mass but has the advantage of compactness which minimizes orbital propulsion makeup, allows a wide envelope for operation around the platform and is not constrained by radiation levels in any direction. For the considerations of reference 3 a shield mass of 35 to 45 tonnes (depending on power level and conversion system) was required to reduce the radiation dose 
rate to $5.7 \mathrm{mrem} / \mathrm{hr}$ at $3 \mathrm{~m}$. While the allowable dose for limited exposure is still under consideration by the National Committee on Radiation Protection, doses in the range of 5 to 25 REM over a period of 1 month to a year appears to be in the acceptable range. This allowable dose must also include that from the natural environment and hence total dose is sensitive to mission orbit and personnel mission activity scenarios. The shadow shielded, boom mounted reactor results in a reduction of shield mass to 12 to $20 \mathrm{t}$ depending on distance, power level and conversion system. In this configuration the shielding only allows continuous exposure on the platform and limited exposure periods in all directions near the reactor. An optimization trade between shield weight versus boom length and boom weight resulted in a boom length of $70 \mathrm{~m}$ and the optimal mode of power transmission is by electrical conduction.

The major problem with an attached reactor is the method of end-of-life disposal which under present SP-100 safety scenarios requires placement in a nuclear safe orbit ( $>300$ year life, for SP-100 Reference Design this requires $400 \mathrm{nmi}$ circular orbit). If the platform mission is in a nuclear safe orbit then the platform could be detached from reactor and moved to a different orbit and a new reactor installed or the reactor could be transported to a different orbit by a remotely controlled cargo vehicle. For orbits below nuclear safe the reactor must be disposed of by methods discussed in reference 4 . However, the present SP-100 safety scenario does not allow operation in other than a nuclear safe orbit and strong mission justification would be required to change that restriction.

\section{TETHERED REACTOR}

In this configuration the entire nuclear electric power system is connected to the platform by a $30 \mathrm{~km}$ flexible tether. The $30 \mathrm{~km}$ length was chosen by nuclear safety considerations involving attachment to a platform in LEO, i.e., nonnuclear safe orbit. At $30 \mathrm{~km}$ if the tether is severed the nuclear system would, by the gravity gradient induced tension, rise to a nuclear safe orbit when an orbit-circularizing burn is added. The "optimal" reactor platform separation is therefore a function of platform orbit. Power transmission by conduction was too heavy for the application due to the long transmission distance. As a result microwave transmission was considered but its low efficiency resulted in the selection of a system utilizing an electrolysis plant at the reactor which produces and pumps gaseous hydrogen and oxygen through hoses to fuel cells on the station. The water produced by the fuel cells is returned to the reactor electrolysis plant for reprocessing. This $\mathrm{H}_{2} / \mathrm{O}_{2}$ fuel cell conversion system also has the advantage of being compatible and synergistic with the platform life support and environmental system.

A disadvantage of the long tethered system is the acceleration on the space platform. This occurs because the reactor/space platform system travels in a orbit corresponding to the balance of gravitational and centrifical forces at the system center of mass. Since forces do not cancel at other locations station microgravity experiments may be affected. Therefore careful consideration of microgravity requirements and reactor/station design must be made. In reference 4 this problem was solved by the use of a countering ballast, however, this greatly increases the weight of the tethered reactor power system and favors reactors on short tethers balanced by ballast on long tethers. 
Table III shows a mass breakdown comparison of the boom-mounted and tethered concepts considered in reference 3 .

\section{Free Flying Reactor}

The advantage of this concept is that the reactor can be placed in a nuclear safe orbit so that operational and starting considerations fully match the present SP-100 safety requirements. A further advantage is the large reduction in shielding since the reactor platform would be only remotely tended. In this concept $\mathrm{H}_{2} \mathrm{IO}_{2}$ is produced by electrolysis on the reactor platform and transported to the main platform by an orbital transfer vehicle which also returns the water produced by fuel cells aboard the main platform.

The main platform was considered to be in a $500 \mathrm{~km}, 28.5^{\circ}$ inclination orbit and initially co-planar orbits at altitudes ranging from 600 to $1200 \mathrm{~km}$ were investigated for the free flying reactor platform.

The problem with this concept is the long periods of time between reactor platform and main platform co-planar orbits resulting in long storage periods between resupply and/or large propellant consumption from the resulting $\Delta V$ requirements. Non co-planar orbits result from the difference in drift rates at different altitudes. A number of reactor platform orbits and transfer strategies were considered in reference 3 . Even in the most optimistic of these scenarios the fuel payload requirement was $230 \mathrm{t}$, the initial mass in orbit was an order of magnitude greater than the tethered system and required an additional 10 year cumulative mass makeup from earth of $730 \mathrm{t}$ a two order of magnitude increase over that required by the tethered system.

\section{Installation, Operation and Disposal Options}

While reference 3 investigated a variety of nuclear power concepts for earth orbiting platforms it did not study the critical questions of installation, platform operation, and disposal methodology. These problems are analyzed in reference 4 in which a 300 kWe system was first considered as being tethered, then as being located on a single boom and lastly as two $150 \mathrm{kWe}$ reactors attached to a dual boom. Human rated shielding configurations were generated for extravehicular activity (EVA), shuttle orbiter approach, docking and departure, and EVA for end-of-life separation and disposal of shutdown nuclear reactor power system. The study confirmed the feasibility of installation, operation and end-of-life disposal for all three concepts.

A number of disposal destinations including nuclear safe orbit, solar orbit, solar impact, solar escape, lunar impact and earth return were investigated. Earth return either by controlled reentry or shuttle return open nuclear safety questions which are as political as they are technical and it does not appear that this technique is acceptable except as a last resort for scientific, economic or political reasons. Nuclear safe orbit requires by over an order of magnitude less propulsive mass than any of the other destinations other than earth return. Hence, nuclear safe orbit appears to be the most favorable method for disposing of the shut down nuclear power system at end-of-life. Reference 4 showed that this could be accomplished for all three attachment concepts with the use of an existing chemical propulsion, shuttlecompatible rocket engine. 


\section{Lunar/Mars Surface Applications}

For earth orbit applications at power levels up to a few hundred kilowatts the advantage of nuclear versus solar power is mainly logistical and hence enhancing rather than enabling. However, as one looks toward the exploration and commercialization of the moon and Mars nuclear becomes the enabling technology on a mass basis for continuous power above several tens of kilowatts. This is due to the massive energy storage requirement resulting from the long lunar ( 14 days) and Martian ( 12 hr) nights.

In reference 5 the mass of nuclear and solar systems are compared for lunar and Mars surface applications. These results are shown in figures 5 and 6 respectively. The state-of-the-art solar power system is a silicon cell array with a specific power of $40 \mathrm{~W} / \mathrm{kg}$ and $\mathrm{NiH}_{2}$ batteries at $40 \mathrm{~W}-\mathrm{hr} / \mathrm{kg}$ rated at 100 percent depth of discharge. The advanced solar power system employs amorphous silicon photovoltaic cells or is an advanced solar dynamic system. In both cases regenerative fuel cells with a specific energy of $500 \mathrm{~W}-\mathrm{hr} / \mathrm{kg}$ (100 percent depth of discharge) are used to store energy for night-time power requirements. Two nuclear systems are shown. One employes a $4 \pi$ shield transported from earth while the other uses a shield manufactured from lunar soil (ref. 6). The data shown in these figures strongly suggests that while precursor lunar and Mars surface power systems will probably be solar, nuclear power will be required for "long term" manned presence and commercialization.

\section{CONCLUDING REMARKS}

As one looks more ambitiously into space and attempts to exploit its economic benefits the requirements for power grows at an ever expanding rate. Soon it will reach a level beyond the reasonable limits for solar devices. Moreover, as our quest expands further into the solar system and beyond, the solar flux drops off rapidly and soon becomes an impractical energy source. Solar powered missions involving long sun/dark cycles such as the 14 day sun/14 day dark lunar cycle require massive energy storage to provide power during the dark phase. This results in mission-limiting mass/cost constraints. Hence, as our space visions expand so does our need for high, long-life, compact, lightweight, continuous power independent of solar orientation, specific orbits or missions and is survivable in natural or hostile environments. These power system requirements are met by nuclear energy sources of the type being developed by the SP-100 space nuclear power system program. 


\section{REFERENCES}

1. "SP-100 Ground Engineering System Project," Annual Technical Progress Report for Oct. 1986 through Sept. 1987, DOE/NBM-1087, (GE Document No. 88-SDS-4214), July 1988.

2. "SP-100 Project Integration Meeting Report," SP-100 Project Integration Meeting, Long Beach, CA, General Electric Co., July 19-21, 1988.

3. Silverman, S.W., Willenberg, H.J., and Robertson, C., "Applicability of 100 kWe-Class of Space Reactor Power Systems to NASA Manned Space Station Missions," 0180-28461-1, Boeing Aerospace Co., 1984, NASA CR-174696.

4. Bloomfield, H.S. and Heller, J.A., "A Feasibility Assessment of Installation, Operation, and Disposal Options for Nuclear Reactor Power System Concepts for a NASA Growth Space Station," NASA TM-89923, 1987.

5. Sovie, R.J., "Power Systems for Production, Construction, Life Support and Operations in Space," NASA TM-100838, 1988.

6. Bloomfield, H.S., "Small Reactor Power Systems for Manned Planetary Surface Bases," NASA TM-100223, 1987.

TABLE I. - KEY SYSTEM PERFORMANCE CHARACTERISTICS

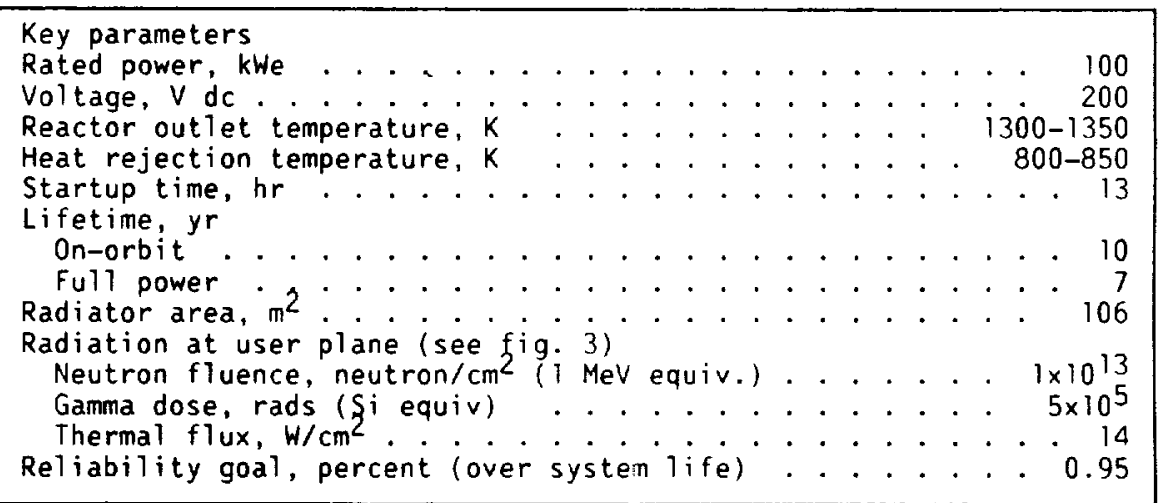


TABLE II. - SYSTEM MASS BREAKDOWN GOALS

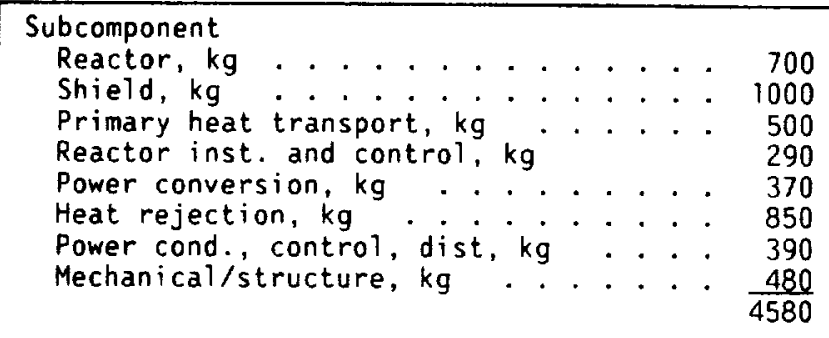

TABLE III. - MASS BREAKDOWNS OF BOOM MOUNTED AND TETHERED REACTOR SPACE POWER SYSTEMS (REf. 3)

\begin{tabular}{|c|c|c|}
\hline & $\begin{array}{c}\text { Boom mounted }(70 \mathrm{~m}) \text {, } \\
\mathrm{kg}\end{array}$ & Tether $\underset{k g}{ }(30 \mathrm{~km})$, \\
\hline $\begin{array}{l}\text { Reactor and power conv. } \\
\text { Shield } \\
\text { Radiators } \\
\text { Electrolyzer } \\
\text { Tanks } \\
\text { Fuel cells } \\
\text { Water } \\
\text { Tether } \\
\text { Trans. 1ines } \\
\text { Boom }\end{array}$ & \begin{tabular}{rr}
1 & 650 \\
18 & 000 \\
871 \\
- \\
\\
\hdashline \\
\\
\\
\end{tabular} & $\begin{array}{rr}2 & 100 \\
2890 \\
1 & 171 \\
1 & 600 \\
4 & 200 \\
3 & 700 \\
15 & 000 \\
7 & 940 \\
- & --0 \\
36 & 601\end{array}$ \\
\hline
\end{tabular}

Instrument rated. 


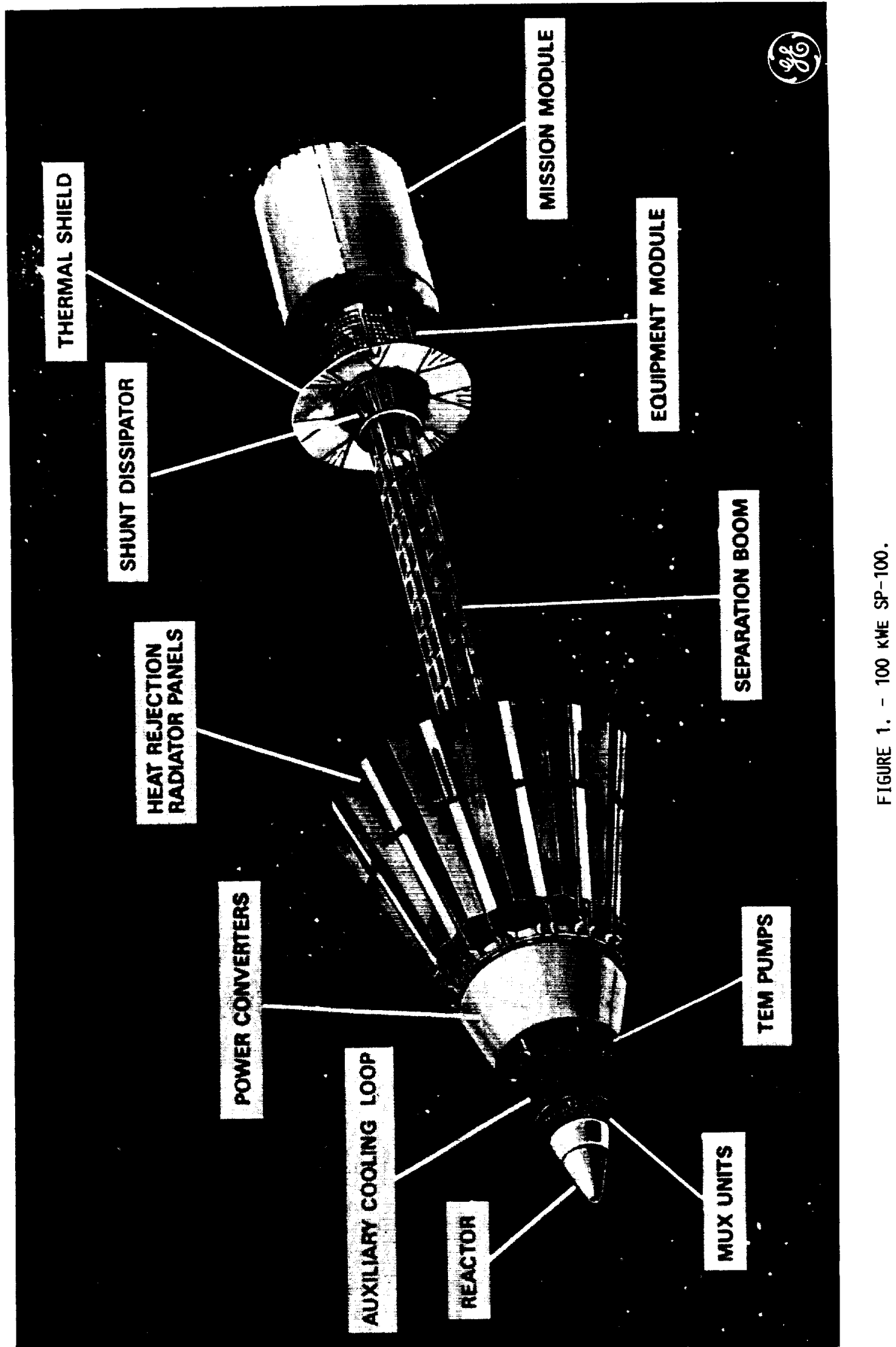




\section{ORIGINAL PAGE IS \\ OF POOR QUALITY}

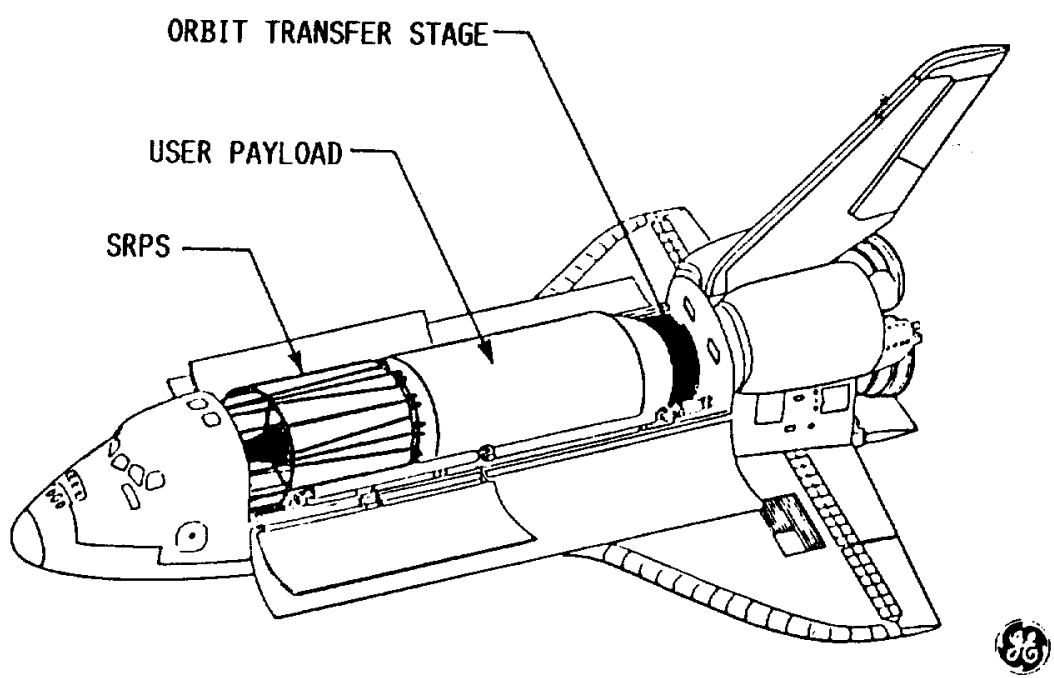

FIGURE 2. - SP-100 AND USER PAYLOAD IN SHUTTLE.

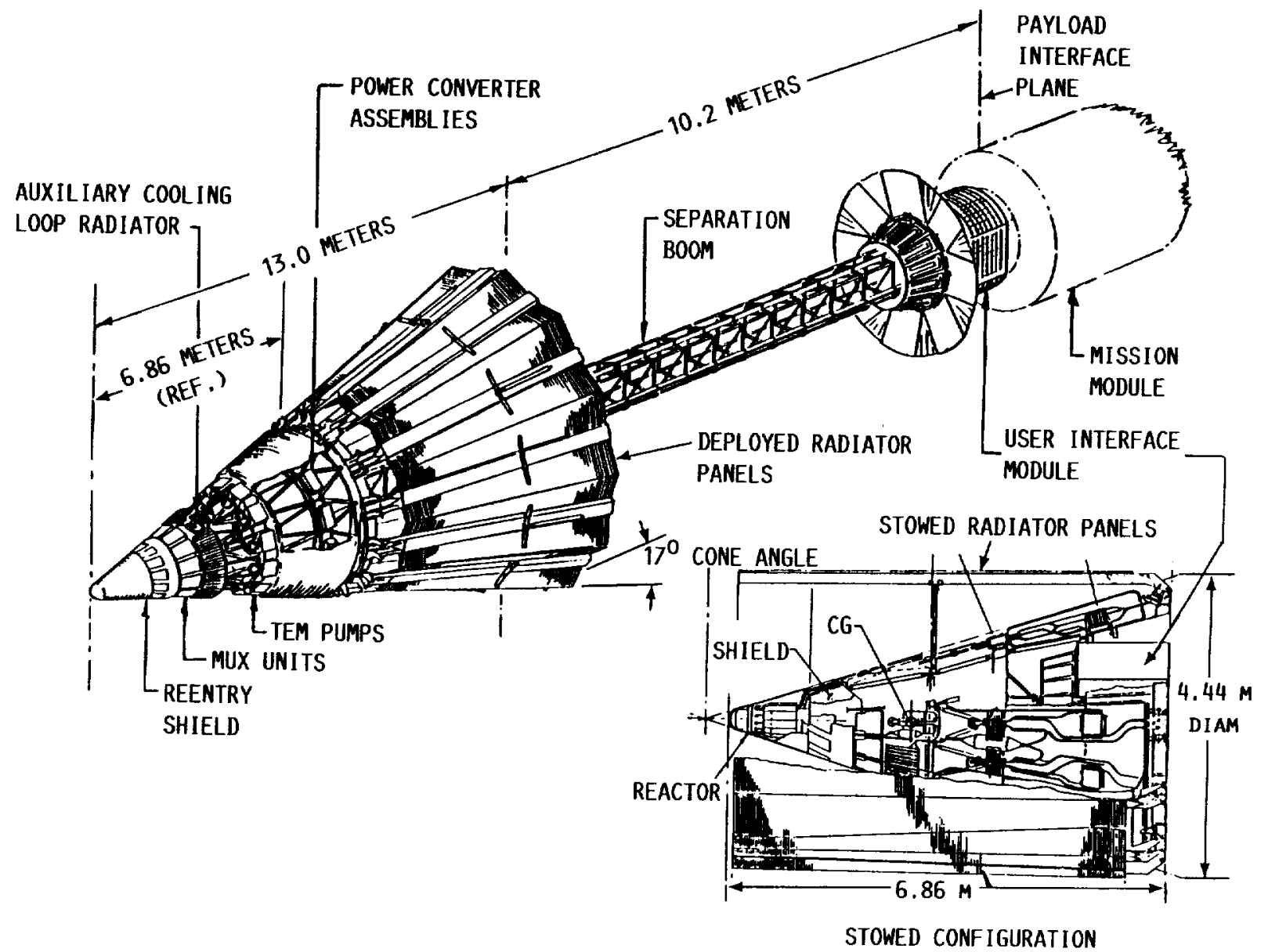

FIGURE 3. - SP-100 STOWED AND DEPLOYED CONFIGURATIONS. 


\section{ORIGIYAL "RGE IS \\ OF POOR QUALITY}

$\because$

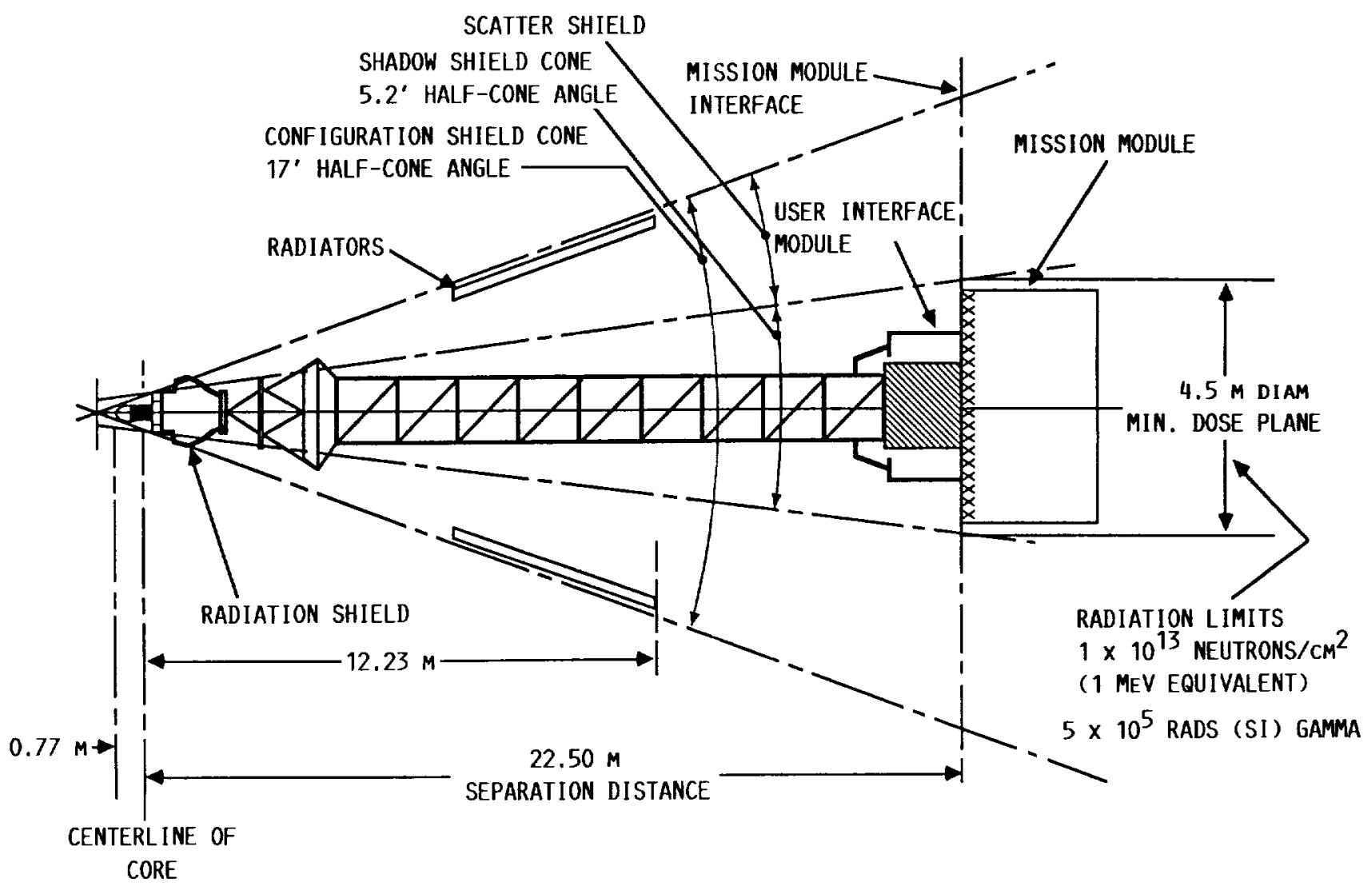

FIGURE 4. - REACTOR RADIATION SHIELD CONFIGURATION. 


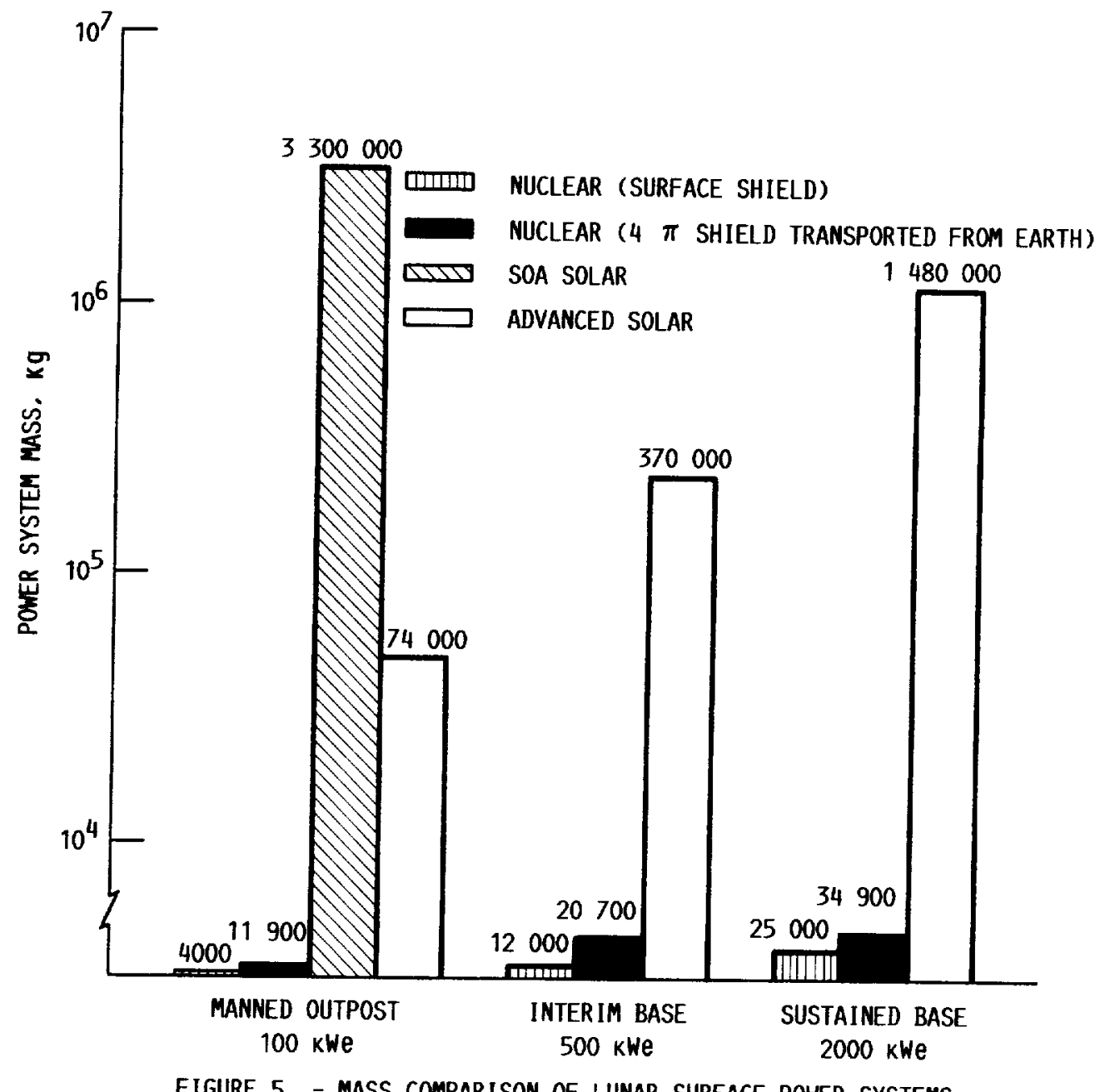

FIGURE 5. - MASS COMPARISON OF LUNAR SURFACE POWER SYSTEMS. 
ORIGINE PASE
OF POOR QUALITY

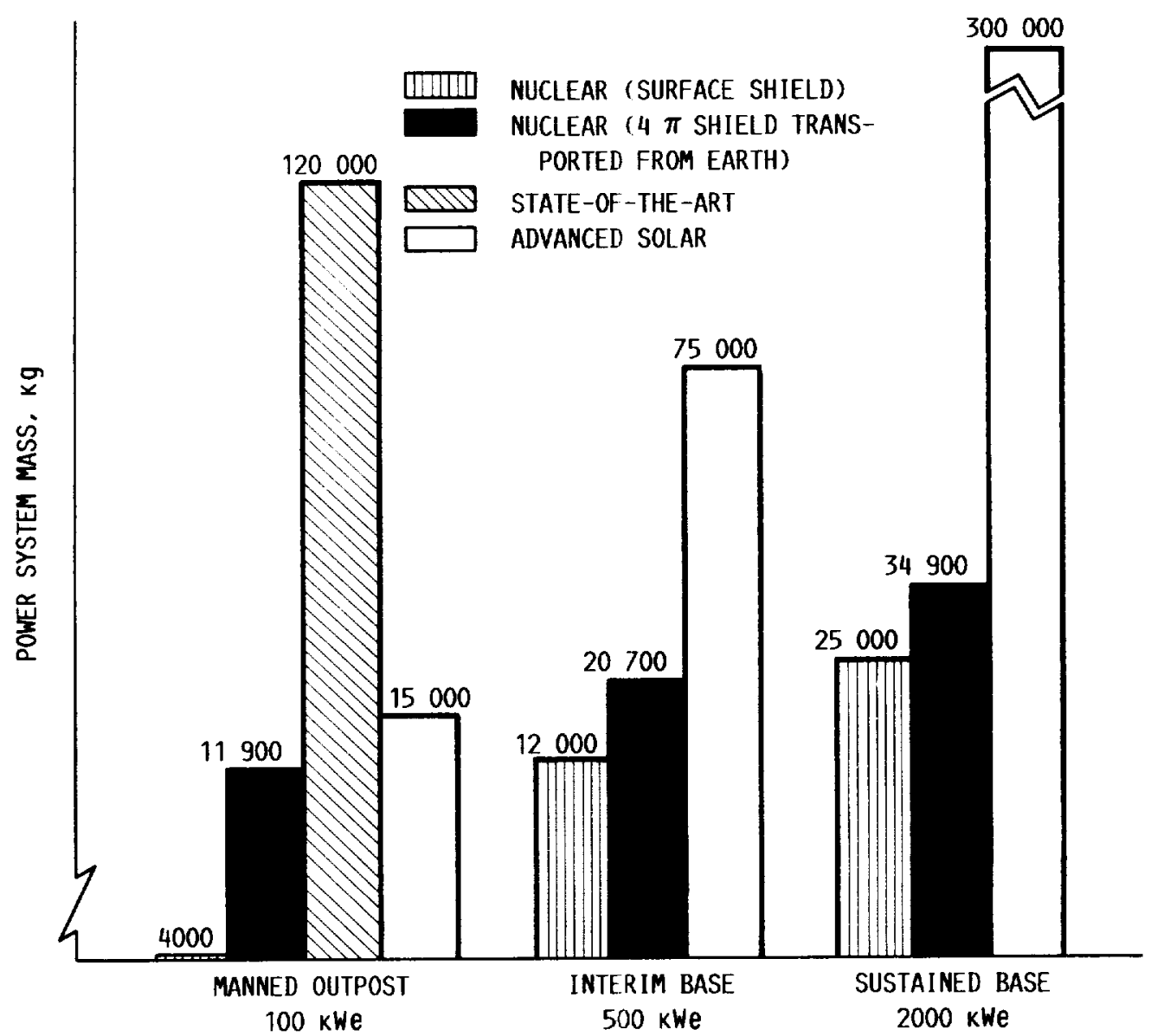

FIGURE 6. - MASS COMPARISON MARTIAN SURFACE POWER SYSTEMS. 


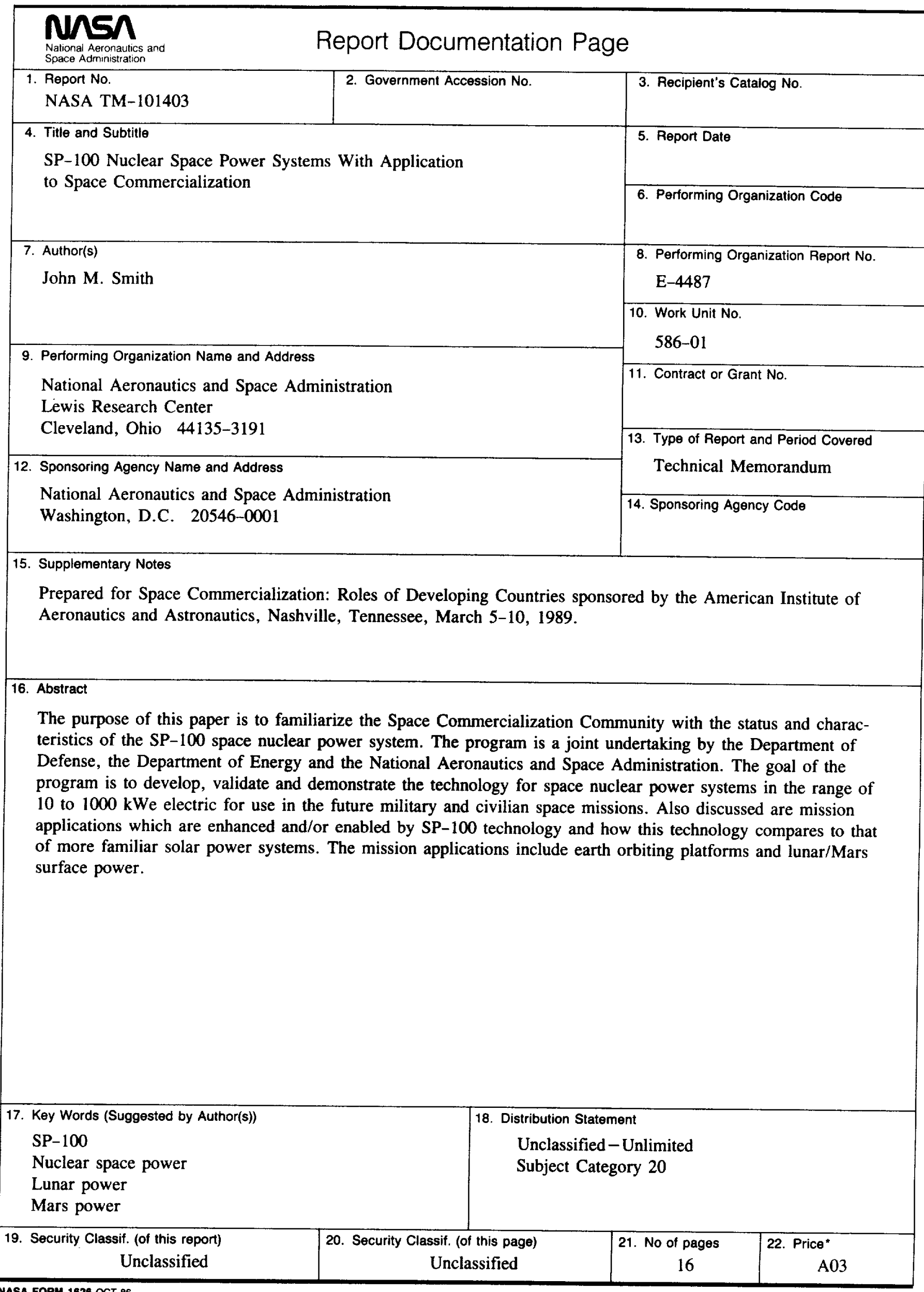

